\title{
The Artistic Charm in Matrilocal Gog
}

\author{
Xiaomin Lei \\ Foreign Language School of Guangdong Ocean University \\ Guangdong Zhanjiang 524088, China \\ E-mail: hezi226@yahoo.com.cn
}

\begin{abstract}
With the creation named Matrilocal Dog, Yoko Yawada won the Akuta Kawa Prize and became known to the public. Interlacing the reality and irreality, the story tells about the relationship between Mitsuko Kitamura, who works as a teacher in a private school and Tarou, a man turned from a dog. This paper will analyze the artistic charm mainly from the story's technique of creation.
\end{abstract}

Keywords: Linkage, Narrative insertion, Matrilocal Dog

\section{Introduction}

Yoko Tawada's Matrilocal Dog, covered in Group Imagery in December, 1992, is a masterpiece full of special artistic charm with which, Yoko Tawada won the $108^{\text {th }}$ Akuta Kawa Prize in the year of 1993 . Being known to everyone in Japan, she still has to be introduced to Chinese readers. Yoko Tawada was born in Tokyo and graduated from the first department of literature in Waseda University. She went to Germany and lived there in 1982. Later she received the master degree in Hamburg University and won the Chamisso Prize for literature in 1996. She writes both in Japanese and German and has a name for her respect to language and her critical attitude towards traditional Japanese language. Short story Saint Gotthard Railway, long story Flying Soul and drama Luminous Crane's False Face are included in her main works.

\section{Main Content}

The story Matrilocal Dog centers on the relationship between the teacher Mitsuko Kitamura and the unknown man Tarou. It begins with the description of the teacher Kitamura by telling that she came to a plot and earned her living by opening a training course for the children in that district. When summer vocation came, a man named Tarou appeared and settled down in Kitamura's house without any modesty. Then they had intimate relationship with each other spontaneously. Tarou was so tame and used to doing the cooking. He liked sniffing. Yet he often went out in the dead of night.

One day, Mrs. Orita, the mother of one of the teacher's students saw Tarou and told the case: Tarou was a following of her husband called Hnuma and already had a wife called Yoshiko. Guided by Mrs. Orita, Yoshiko came to the teacher's home and recognized the man was her husband Tarou Hnuma, yet she didn't speak out on the spot. She asked the teacher to come to her house the next day and told her the whole story about Tarou and herself. Besides, she also told the truth of the secrete meeting at night between Tarou and Toshio Matsubara. The girl called Fukiko, always has been tormented by classmates and loved by the teacher, was the daughter of Toshio. She was brought up by her father Toshio after her mother died.

At the end of the story Tarou and Toshio both disappeared and the teacher ran away with Fukiko.

It seems that the complicated relationship among the characters makes people suffocate. Yoko Tawada used various styles and fashions to make her creation Matrilocal Dog decadently charming. There are almost long sentences in this story with hardly any full stop. The matrilocal dog with homosexual-prone and the ran away teacher with a little girl seem never appear before, "from then on, scarcely anyone had ever come to the south district." It looks like that those people were covered by a dark fog and faded away. Though the end comes, you still can stretch your imagination to feel the illusive mythical color, which is the special artistic charm of this story.

Uniting the folktale and the modern residential district skillfully, Matrilocal Dog shows the modern society existing between illusion and reality. Yoko Tawada expresses her unique experience of life through using multiple experience of body such as sense of vision, hearing, touching, tasting and smelling. The nonstandard expression can set off the atmosphere of this story by contrast on real and unreal perfection. Some people criticized that this story staked the field of standard contemporary fiction and can be called as a "brand new fiction". Yoko Tawada's fictions have the supreme artistic charm in the way of conception. 


\section{Analysis of the Way of Creation}

\subsection{Linkages}

There is a deep origin between China and Japanese. For the reason of transnational communication in literature, the culture between this two countries and the way of creation of the writers in these two countrys have a lot in common.

In the whole story, despite the complicated relationship of the characters, the plot is also complex. In fact, the writer used a technique of linkage to make the narration. Several stories are linked with each other but independent and interlaced on the other hand. Inside the main story there are other subordinated stories. The unknown origin of the characters seems to appear suddenly and disappear suddenly, which makes the reader confused but keeps them within bounds when it is understood. The successful point of this story is that it caters for readers' expectation. The writer sets suspense to make a strong contrast between readers' expectation and the sudden ending, which leaves questions to readers.

The plots in Matrilocal Dog are linked together in which the plot of Mitsuko Kitamura and Tarou is the most important. It is the major one on which the whole story is centered. Yet, inside this plot exist the stories of Tarou and his wife Yoshiko, the story of Tarou and his lover Toshio Matsubara and the story of Kiramura and Fukiko.

Similar to the way of linkage is the work Ashes of Eaglewood-the Second Burner of Zhang Ailing. In this book, the main setting goes with a story told by Clementine. Yet under which exist different situations: the "inside" caused by the two main characters-Roger and Susie - their wedding - Mrs. Michelle's education of sexology towards the sister Frances and Susie; Frances and her husband Frank's marriage and the latter's death; Frances's education before marriage toward Susie.

The writers of the two stories set the whole structure like building maze. You will have to dig and seek inside them step by step like a detective clearing up a case to find the truth because the plots that are linked interlaced. However, when it comes to the ending, there are differences between the two stories. In Matrilocal Dog, the two characters disappear at last, while in Ashes of Eaglewood- the Second Burner, the hero commits suicide.

\subsection{Narrative Insertion}

In Matrilocal Dog, the writer used a special way, that is narrative insertion. At the beginning of the story, the teacher Kitamura tells a tale about a matrilocal dog-people have intimate relationship like the animal with her students. Coincidently, the story tells the very tale - the relationship between the teacher Kitamura and the doglike man Tarou. Is it a real story or just a fairy tale created by the writer? It evokes the readers' strong thought fluctuation. This special technique unites the real and unreal, the absurd and the reality and provides readers multiple angles of thought conversion. When using this technique, Yoko Tawada sets a foreshadowing at the very beginning and leads readers to consider whether it is the case. Also, the foreshadowing plays an important role in readers' receiving the ending. In the story, after hearing the tale of matrilocal dog, the children are unable to retell the whole story without anything missing due to their lacunae of the memory, which leads two different situations of the story. Like the ending of story, the readers can just give the characters an ending by their imagination.

Bajin also used this technique to implicate the ending of the character in his novel Family. First it shows Juehui's opinion about the characters in Treasure Island. He thinks the hero is a "black dog", who is not as gentle as Dr. Lee. Being Gentle is useless while those who don't obey the rules of the society like black dogs are useful. Juehui's such opinion has something to do with the proneness of Family in which the bold traitor Juehui is somebody while Juexin, who scrupulously obey the salutations is nobody. And at the end Juehui's leave is the very heroic behavior as a matter of course.

Second, when telling the story, the writer mentions Tolstoy's Resurrection many times especially when Juehui decides to give up Mingfeng and chooses business. Juehui's subconscious forms a one-to-one correspondence in mapping with Nekhledov. Even in the dream, Juehui still gives a fig for Mingfeng's position as a soubrette. His belief in business first shows his mind of business is more important than Mingfeng and he doesn't show enough respect to Mingfeng. When he is deep in thought after hearing the Resurrection, that is when he is thinking whether he has the right reason to give up Mingfeng, we can consider that Juehui's subconsciousness doesn't allow him to give it up and he is confessing for the abundant. He has to resurrect thought in some ways.

Compared with this two stories, Yoko Tawada uses the narrative insertion to serve the whole structure and the insertion itself is just prophesy to tell the ending of the story. Matrilocal Dog joints the folktale and the whole story to present a real modern society in shadow land. The nonstandard expression can set off the atmosphere of this story by contrast on real and unreal perfectly. Yet Bajin's Family places special emphases on characters and the movement of the whole matter. Above is the difference in using narrative insertion in the two stories.

\section{Conclusion}

Yoko Tawada uses the techniques of linkage and narrative insertion skillfully in Matrilocal Dog and presents to the 
readers a creating angle of the writers in contemporary Japan. In literature creating, Yoko Tawada shows her special vision and leaves readers unlimited thinking.

\section{References}

Chen Fang. (2007). Research of Modern Russian Feminine Novels. China People Publishing Company.

Limo. (2006).On Development of Japanese Feminine Literature From the Transmutation of "Family Conception". Foreign Literature Research. 03

Lin, Danya. (2003). History of Modern Chinese Feminine Literature.

Lin, Yutang. (2004).Feminine Life. Shaanxi Normal University Publishing Company.

Liu, Chuanxia. (2007). Women being constructed: Research on Social Sex of Modern Chinese Literature. Qilu Publishing Company.

Wang, Zongjie. (2005). On Features of Modern Japanese Feminine Literature. Journal of Northeast Normal University(Edition of Philosophy \& Social Science).5, pp. 5-217.

Yoko Yawada. translated by Weng Jiahui. (2001). Matrilocal Dog.China Literary Federation Publishing Company.

Zhang Lan. (2007). A Century's Chinese Feminine Literature under the Local View. China Social Science Publishing Company. 